Advances in Dynamical Systems and Applications.

ISSN 0973-5321, Volume 16, Number 1, (2021) pp. 189-200

(C) Research India Publications

\title{
The Study the Influence of the Parameters of the Operating Elements on the Technological Indicators of the Operation of the Greenhouse Soil Loader and Mixer
}

\author{
A.O. Vezirov \\ N.I. Vavilov Saratov State Agrarian \\ University, Saratov, Russia,
}

P.I. Pavlov

N.I. Vavilov Saratov State Agrarian

University, Saratov, Russia,

\author{
G.V. Levchenko \\ N.I. Vavilov Saratov State Agrarian \\ University, Saratov, Russia, \\ E.E. Demin \\ N.I. Vavilov Saratov State Agrarian \\ University, Saratov, Russia,
}

\begin{abstract}
Preparing and using soil in greenhouses is a laborious and energy consuming process. The lack of specialized technical means hinders obtaining the required quality of soil mixtures. For mixing and loading soil components for greenhouses, a mixer-loader with a screw milling operating element has been developed. One of the main stages in the development of new designs is to determine the main design parameters of the screw-milling operating element, which is the main in the mixing process. The theoretical and experimental studies established the influence of the parameters on the indicators of the efficiency of the preparation of soil mixtures and substantiated their rational values. The shape of the cutting teeth installed on the screw-milling operating element is substantiated. As a result of research, technological indicators were obtained: the mixing quality factor is $0.96 \ldots 0.98$, the moisture and air capacities of the resulting soil mixtures reach 51 and $48 \%$.
\end{abstract}

Keywords. Soil, soil mixture, greenhouse, mixer-loader, screw-milling operating element. 
Introduction. Growing plants in greenhouses using soil mixtures consisting of natural components is subject to a number of agrotechnical requirements such as nutrient content, a high mixing ratio, high moisture and air capacity. Moisture capacity is the ability of the soil to absorb and retain moisture. Air capacity is the volume of soil pores containing air at soil moisture corresponding to its lowest moisture capacity. It is expressed as a percentage of the soil volume [1].

The existing technological means used for the preparation of soil mixtures have a number of disadvantages. In particular, stationary mixers, for example STM-80, have low productivity, high material and energy consumption. Mobile continuous loaders, for example PND-250, have high productivity, but at the same time, low mixing quality, and as a result, the physical properties of the soil deteriorate. In addition, these machines have a large metal consumption, dimensions (unsuitable for indoor operation) and are aggregated with tractors of a high traction class [9, 10], while in greenhouses specialized tractors of small dimensions and power are used.

Thus, obtaining soil mixtures with high quality and corresponding to agrotechnical requirements requires developing and studying the operating elements of a new machine.

Material and Methods. To eliminate the disadvantages inherent in analogs, a specialized semi-mounted soil mixer-loader for greenhouses has been developed [2, 3]. It is proposed to use the loader as part of a machine line according to the developed technology [4].

The mixer-loader captures and stirs soil components with the main operating element auger cutter. The screw-milling operating element is equipped with teeth with cutting surfaces of a special shape [5]. The teeth provide the separation of parts of the components from the main body, their crumbling and subsequent mixing [7].

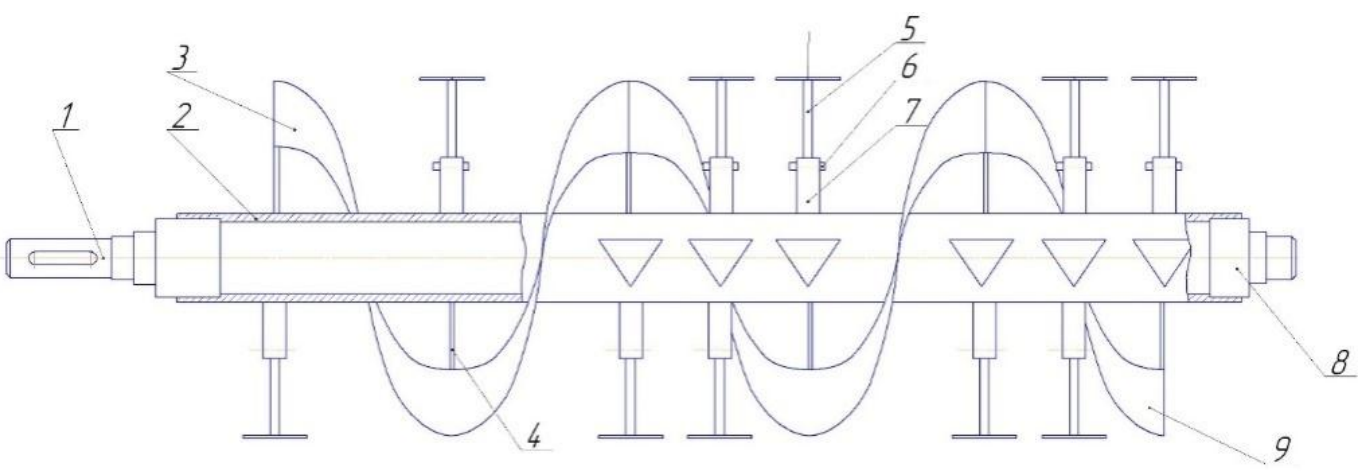

Figure 1 - Auger operating element.

1 - drive neck, 2 - shaft, 3 - helical blade, 4 - bar, 5 - tooth with a stand, 6 - pin, 7 - base, 8 - neck, 9 - shortened blade. 
One of the main stages in the development of new designs is to determine the main design parameters of the screw-milling operating element, which takes the main part in the mixing process.

The design parameters include the diameter of the screw $\mathrm{D}$, the width of capture $\mathrm{B}$, the angle of inclination of the screw surface, as well as the parameters of the cutting teeth (Fig. 2): tooth width $B_{t}$; height along the leading and trailing edge $h$; thickness $b$; the length of the horizontal projection $l_{h}$; the radius of the bendable circle $R_{t}$ (for the curved surface of the teeth). In addition to linear parameters, the cutting teeth parameters include the angle at the top of the tooth $\gamma$, the angle of sharpening $\alpha$. The above parameters make it possible to fully describe the interaction of the operating element with the components of the soil mixture.
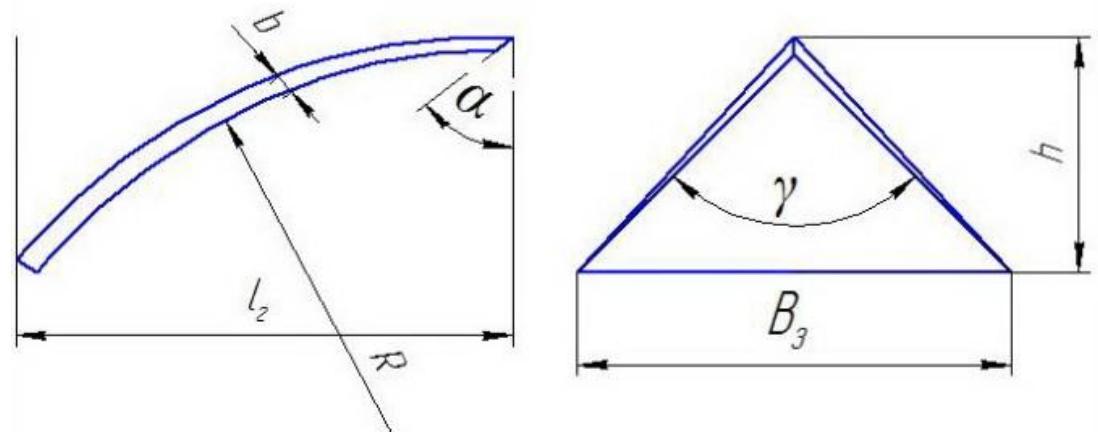

Figure 2 - Parameters of the teeth of the screw operating element of the mixer-loader.

The interaction of the operating element with the components of the soil mixture begins with the introduction of the teeth. The tooth is introduced with the cutting edge. Let's select an elementary soil fragment on the cutting edge and consider the effect of forces on it (Fig. 3). When a tooth is introduced, an elementary fragment will be clamped between the cutting edge of the tooth and other soil elements. The introduction of an elementary tooth width $d B$ will be counteracted by a reaction $d \bar{R}$ deviated from the normal by an angle $\varphi_{f r}$, which is associated with the action of the sliding friction force $d \bar{F}_{m p}$ along the cutting edge of the tooth. The reaction $d \bar{R}$ is due to the resistance of the soil to penetration, which is determined by the cutting stress on the elementary site $d A$, i.e. $d R=\sigma_{p} d A$ where $\sigma_{p}$ is the cutting stress of soil components, MPa.

Then the resistance to the entire cutting edge of the tooth, $(\mathrm{N})$ :

$$
R_{p}=\sigma_{p} A=\sigma_{p} B b,
$$


where $B$ is the width of the tooth, mm;

$b$ is the cutting edge thickness, $\mathrm{mm}$.

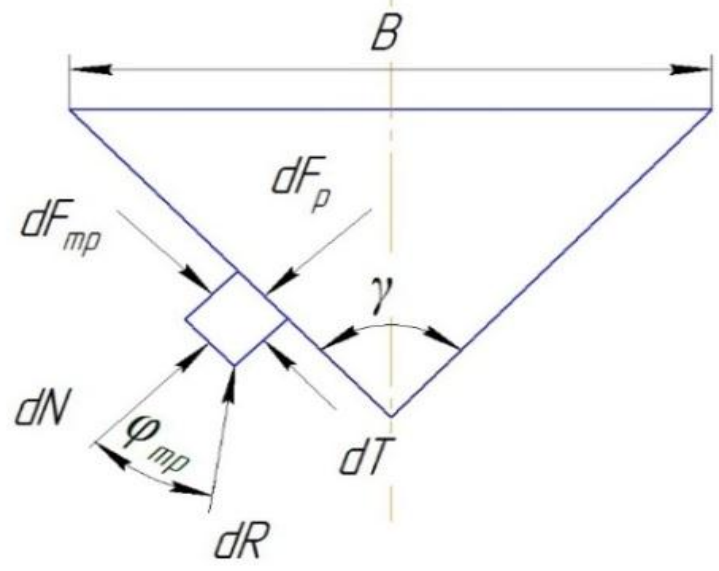

Figure 3 - A scheme of tooth introduction forces.

Tooth force, $(\mathrm{N})$ :

$$
F_{3}=R_{P} \cdot \sin \left(\varphi_{m p}+\frac{\gamma}{2}\right)=\sigma_{p} b B \cdot \sin \left(\varphi_{m p}+\frac{\gamma}{2}\right)
$$

where $\varphi_{f r}$ is the angle of friction of the soil against steel; $\gamma$ is the angle at the apex of the tooth.

The total cutting force of all teeth at the moment of time $t,(\mathrm{~N})$ :

$$
\sum F_{3}=z_{t} \sigma_{p} b B \cdot \sin \left(\varphi_{m p}+\frac{\gamma}{2}\right)
$$

where $z_{t}$ is the number of teeth in the mass of the load at the moment of time ${ }^{t}$.

Equation (2) justifies the angle $\gamma$ for various materials. Black soil, peat, rotted manure, sand are used as the initial components for the soil mixture. These materials are the most common in greenhouse production.

Torque on the shaft of the operating element with a continuous introduction of cutting teeth over the working width:

$$
T=\sum F_{3} Z \frac{D_{p}}{2}
$$

The power spent to separate the components by the teeth will be determined by the 
formula:

$$
P_{p}=\sum F_{3} v_{3}=\frac{z_{3}}{4} \sigma_{p} b B \sin \left(\varphi_{m p}+\frac{\gamma}{2}\right) v_{3}
$$

where $z_{t}$ is the total number of teeth installed on the working body.

The influence of the tooth parameters on the mixing quality is related to the trajectory of the particles along the tooth surface after separation, which in turn is determined by the tooth geometry.

Let us consider the main trajectories of particle motion. With a flat tooth with a $90^{\circ}$ angle to a radius, the material to be separated slides over the tooth surface (Fig. 4). In this case, no crumbling occurs during separation, the material is fed to the auger in large pieces. This form is optimal in terms of the minimum implementation effort and therefore has become the most widespread. However, due to separation in large pieces, it does not provide a good mixing quality of the components of the soil mixture. With a flat tooth with an angle of less than $90^{\circ}$, the trajectory of movement looks like a broken line (Fig. 4, b). At the point of transition from one area to another, internal stresses arise in the material, leading to some crumbling. The degree of crumbling in this case is also low.

The most effective in terms of the degree of crumbling is the curved shape of the tooth surface. Fig. 4, c shows the shape of the tooth in the form of a cylindrical sector. Since the detachable components are under constant influence from the surface of the tooth, internal stresses arise in the material, leading to its crumbling.

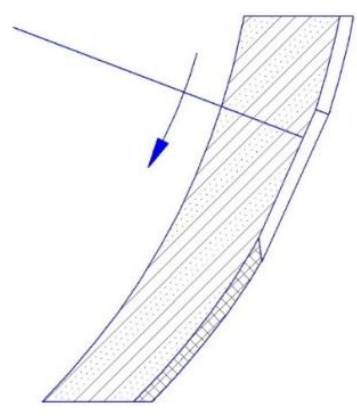

a

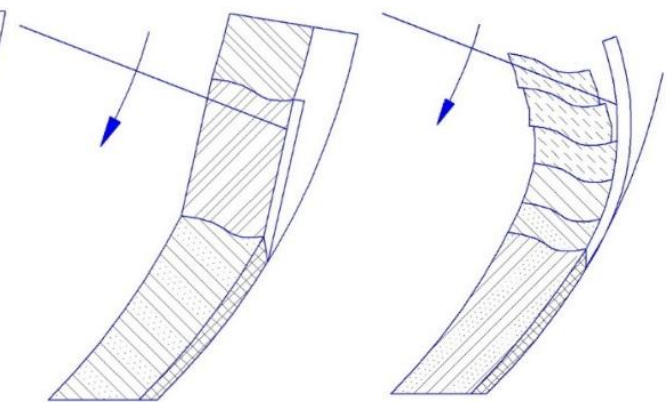

b c

Figure 4 - Interaction of teeth of various shapes with a component of the soil mixture during separation: a - flat tooth shape, with a $90^{\circ}$ angle to the radius; $\mathrm{b}$ - flat tooth shape, with an inclination angle to the radius of less than $90^{\circ} ; \mathrm{c}$ - curvilinear shape in the form of a cylindrical sector. 
The mixing quality depends on the degree of crumbling of the soil components. With a high degree of crumbling, the components during movement mutually penetrate and mix with each other. In turn, the degree of crumbling directly depends on the force transmitted to the soil components when the working body tooth interacts with them. The force is limited by the action of the leading edge of the tooth on the material, i.e. the effort transferred to the separated part of the components of the soil mixture will be determined by expression (2).

Further, the components slide along the tooth surface. In this case, no transfer of force to the separated material as well as additional crumbling occur.

If setting the tooth at an angle less than 90 degrees (Fig. 4, b), the separated layer of the component changes direction of movement when entering the tooth surface and when leaving it. This increases the force transmitted to the material to be separated:

$$
F_{\Sigma}=F_{\kappa}+F_{f r}=\sigma_{p} B b+k_{f} g m f
$$

where $m$ is the weight of the separated component, $\mathrm{kg}$,

$f$ is the component against steel friction coefficient,

$k_{f}$ is the coefficient of influence of the position of the tooth.

However, changing the nature of the movement needs to significantly reduce the angle of inclination of the tooth, which will worsen the separation process.

The maximum crumbling occurs when the teeth are curved (Fig. 4, c). In this case, the area of interaction of the tooth with the component to be separated is much larger, respectively, the force transferred to the material is greater.

$$
F_{\Sigma}=F_{\kappa}+F_{f r}+F_{3}=\sigma_{p} B b+k_{f g m f}+\sigma_{c o m p r} A_{t}
$$

where $\sigma_{\text {comp }}$ is compressive stress at which the destruction of the separated component of the soil mixture occurs, $\mathrm{Pa} ; A_{t}$ is the surface area of the tooth interacting with the material to be separated, $\mathrm{m}^{2}$.

The tooth surface follows a defined curved profile. The simplest to manufacture is a cylindrical profile. In this case, the curvilinear shape of the teeth is determined by the radius of curvature of the tooth $R_{t}$ (Fig. 4). The curvature radius of the tooth is the radius of the generating cylinder that significantly affects the process of separating the components from the array. In addition to the radius, the center of the generator cylinder relative to the center of the working body also affects. The parameters of the center of the generator cylinder location depend on the radius $R_{t}$ and are determined from the analysis of the tooth setting (Fig. 5). The parameters $m_{r}$ and $h_{r}$ should provide the required angle of entry $\beta$ of the cutting edge into the components of the soil mixture. The angle of entry $\beta$ is the angle between the radius of the tool and the tangent to the 
cutting edge. If the angle $\beta=0$ degrees, then the center of the generating cylinder is located on the radius of the operating element, going to the cutting edge. At this angle, the area of penetration of the cutting edge is the smallest and the least resistance to penetration of the tooth into the soil components is provided. As the angle $\beta$ increases, the area with which the cutting edge penetrates into the material increases, and the cutting force increases accordingly.

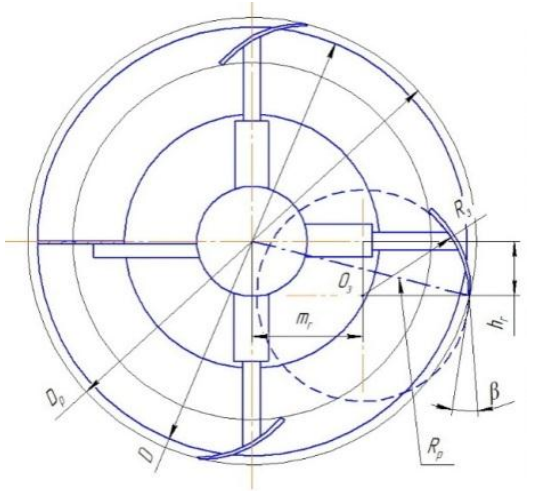

Figure 5 - The tooth positioning scheme.

The curvature radius of the teeth is associated with the stress state that occurs when the teeth interact with soil components. When the working body rotates, the material, after being cut off by the cutting edge, copies the surface of the tooth. In this case, deformations occur in the chips, the curvature of the tooth should be such that residual deformations occur in the chips, which form cracks.

Material and Methods. To confirm the theoretical conclusions, a prototype of a mixer-loader was made. The auger operating element of the mixer-loader was equipped with the rows of cutting teeth, and three cutting teeth and an auger fastening stand were installed in the diametrical section at 90 degrees.

Three forms of cutting teeth were selected and manufactured for research (Fig. 6) - flat with a $90^{\circ}$ angle to the radius of the screw, flat with a $70^{\circ}$ angle of inclination, and curvilinear, in the form of a sector of a cylindrical surface. In experimental studies, the operating element was sequentially equipped with the teeth of the above mentioned forms.

The screw rotation speed, forward speed of the mixer loader and the number of teeth remained unchanged throughout the experiment. Their values corresponded to rotation frequency $\mathrm{n}=300\left(\mathrm{~min}^{-1}\right)$, translational speed $\mathrm{V}=3 \mathrm{~m} / \mathrm{s}$, number of teeth $\mathrm{z}=27$. 


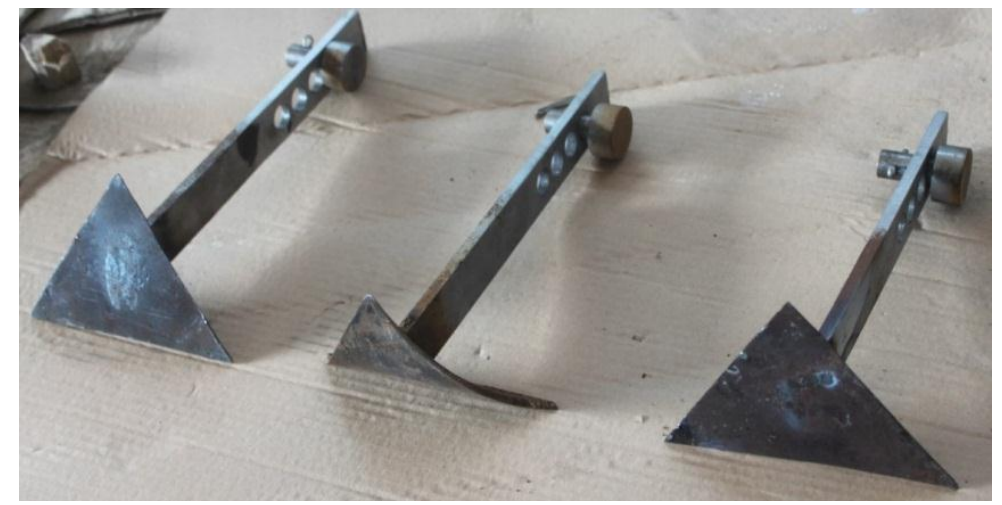

a

b

$\mathrm{c}$

Figure 6 - The studied forms of the teeth: a - flat with a $90^{\circ}$ angle of inclination to the rack axis (radius of the operating element); b - curved in the form of a sector of a cylindrical surface; $\mathrm{c}$ - flat with a $70^{\circ}$ angle of inclination to the rack axis (radius of the operating element).

The soil mixture consisted of three components: black soil, sand, and rotted manure $[6,8]$. The layer thickness of each component is determined according to the required soil mix. In experimental studies, soil was laid manually on the site in layers. The laying lengths ranged from 20 to $30 \mathrm{~m}$. New, untreated components were used for each laying.

As mixing quality, moisture capacity, and air capacity are difficult to determine, their determination was carried out at a certified laboratory of Sovkhoz-Vesna greenhouse farm (Saratov). For this, after each experiment, samples were taken (Fig. 7) of the resulting soil mixture. The number of samples taken corresponded to the required reliability of the results.

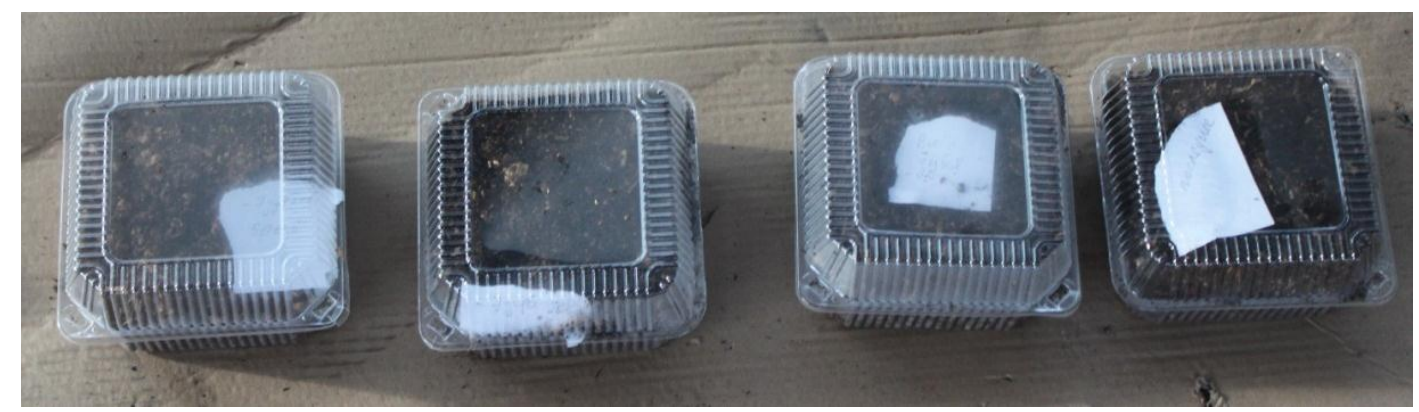

Figure 7 - Samples of the soil mixture taken to determine the physical, mechanical, and technological properties.

Results of the experimental studies. A series of one-factor experiments found the influence of the shape of the teeth on mixing (assessed by the mixing ratio K), as well 
as on the technological parameters of the soil mixture: moisture capacity $\mathrm{W}_{1}(\%)$ and air capacity $\mathrm{W}_{2}(\%)$.

During operation of the auger operating element, the teeth $[11,12]$ are embedded in the massif, separate and destroy parts of the components and partially mix them. Then, during transportation by the screw surface of the screws, the components are additionally mixed. As a result of the operation of the mixer loader, a well-mixed soil mixture is obtained, ready for use in greenhouses (Fig. 8).

The results of studies of the shape of the teeth are presented in the form of diagrams in Figures 9-11. Figure 9 shows the mixing ratio values corresponding to the tooth shapes shown in Figures 4 and 6.

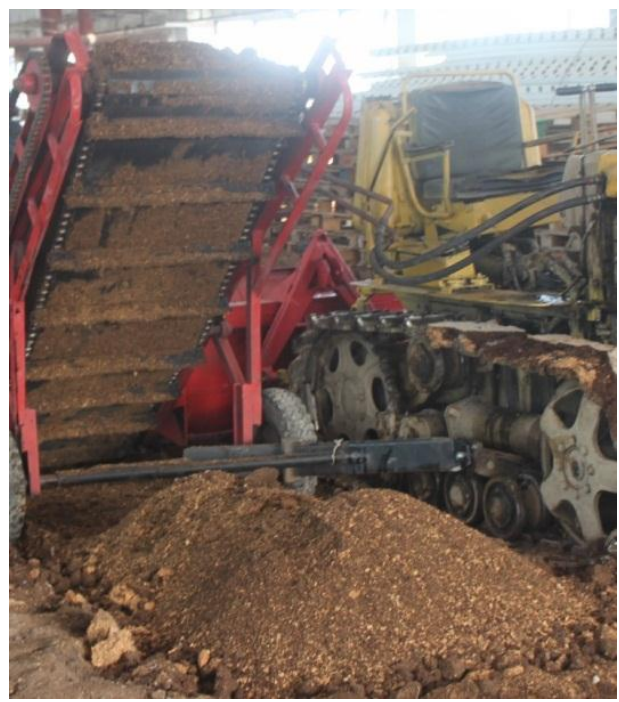

Figure 8 - Soil mixture prepared by a mixer-loader.

The analysis of the obtained results shows that the greatest degree of mixing of the soil components is achieved with the shape of the teeth corresponding to the cylindrical surface curved in the form of a sector. The curvilinear shape, in contrast to the flat one, along with the separation of parts of the components from the solid, ensures their crumbling and mixing before the screw surface of the screws starts to work. The screw additionally mixes the components. The value of the mixing ratio of the components of the mixture was $0.96-0.98$, which is higher than the agrotechnical requirements by 0.9 0.95 . 


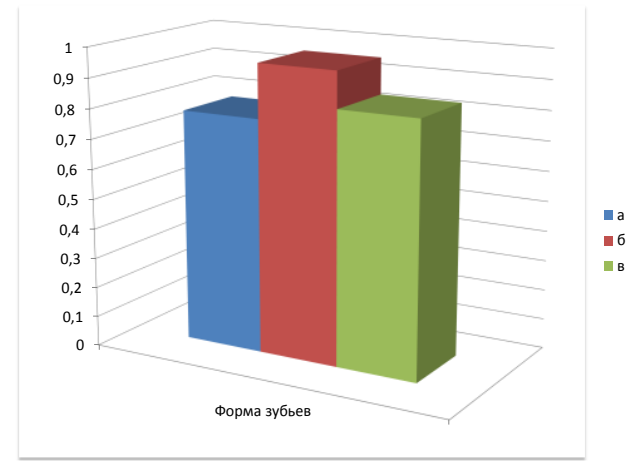

Figure 9 - Mixing coefficient for different tooth shapes.

The influence of the shape of the teeth on moisture capacity is practically the same (Fig. 10), which is associated with a lesser effect on its value of the degree of crumbling. However, the influence of the shape of the teeth on the air capacity is more significant (Fig. 11). Air capacity is more dependent on the degree of crumbling. The obtained values of air capacity and moisture capacity also meet the requirements for soil mixes for greenhouses (moisture capacity not less than 40\%; air capacity not less than 25\%). It should also be noted that these criteria change downward during storage for a long time. Therefore, after storing the soil mixture, loading must be carried out also with the proposed mixer loader to restore quality.

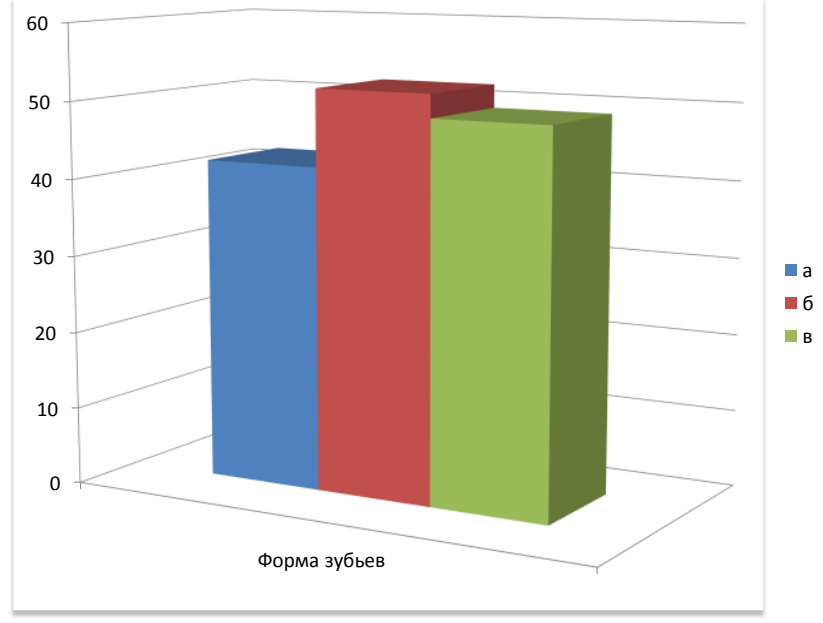

Figure 10 - Influence of the shape of the teeth on the moisture capacity of the soil mix. 


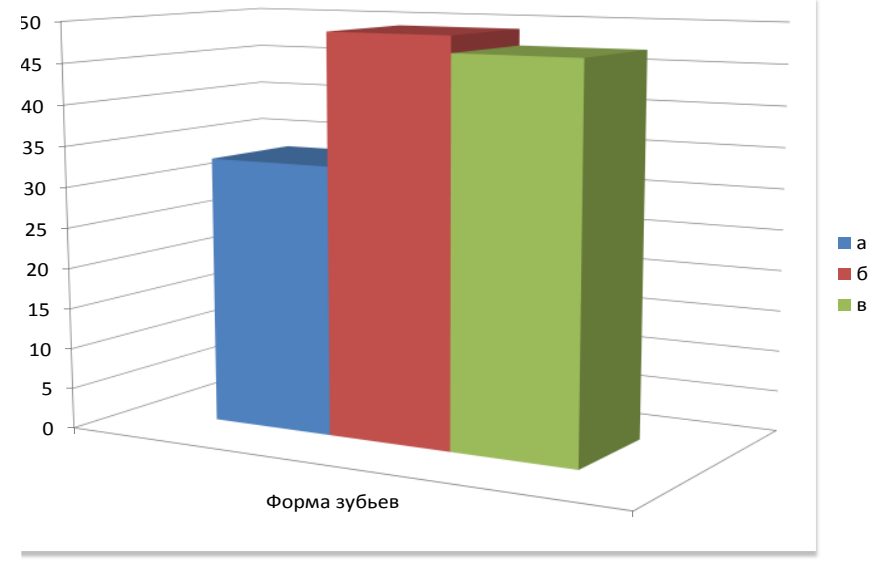

Figure 11 - Influence of the shape of the teeth on the air capacity of the soil mix.

Summary. Thus, the study proved that the greatest efficiency of the preparation of the soil mix in terms of technological parameters is provided by the auger operating element equipped with curved cutting teeth in the form of a cylindrical sector. Analytical expressions are obtained that allow to substantiate the parameters of the cutting teeth. Experimental studies have established the performance indicators of the proposed mixer-loader. The mixing quality factor is $0.96-0.98$. The moisture content and air capacity of the resulting soil mixts reach 51 and $48 \%$, respectively.

\section{REFERENCES}

[1] Vezirov A.O. Improving the production efficiency of soil mixtures by substantiating the design and operating parameters of the mixer-loader: Author's abstract, Candidate of Engineering Sciences / Vezirov A.O. - Saratov, $2013-126 \mathrm{p}$.

[2] Pat. No. 119337 Russian Federation, IPC B65G 65/22, A01C 3/04. Loadermixer for organic-mineral compost / Vezirov A.O., Dziuban I.L., Pavlov P.I.; No. 2012114293/11; declared 11.04.2012; publ. 20.08.2012, bul. No. 23.

[3] Pavlov P.I. Loader-mixer for a greenhouse substrate / P.I. Pavlov, G.V. Levchenko, A.O. Vezirov // Innovations and actual problems of engineering and technology, Proceedings of the All-Russian Scientific and Practical Conference of Young Scientists. - Saratov: ed. SSTU, 2010.- Volume 2.- p. 91-92.

[4] Pavlov P.I. A set of soil operating machines in greenhouse production / P.I. Pavlov, A.O. Vezirov, A.V. Rakutina, D.V. Mukhin // Agricultural scientific journal. - 2016. - No. 7. - p. 51-33. Saratov, 2016

[5] Utility patent No. 117906; IPC B65G 67/24, 65/22; The operating element of 
the mixer-loader / Pavlov P.I., Levchenko G.V., Vezirov A.O., Dziuban I.L., publ. 10.07.2012, Bul. No. 19.

[6] Pavlov P.I., Dziuban I.L. The results of the study of the degree of mixing of the mixer-loader for the preparation of organic-mineral compost [Text] / P.I. Pavlov, I.L. Dziuban // Bulletin of N.I. Vavilov Saratov State Agrarian University. - 2014. - No. 8. - P. 50-51.

[7] Pavlov P.I., Vezirov A.O., Dziuban I.L. Theoretical study of the interaction of the screw operating element of the mixer-loader with the components of organic-mineral compost [Text] / P.I. Pavlov, A.O. Vezirov, I.L. Dziuban // Nauchnaia Mysl. - 2015. - No. 3. - P. 131-134.

[8] Pavlov P.I. Physical and mechanical properties of agricultural freights. / Pavlov P.I., Demin E.E., Shok O.V. - Saratov, 2006. - 130 p.

[9] Pavlov P.I. Organic fertilizer loader [Text] / P.I. Pavlov, R.R. Khakimzianov // Rural machine operator. - 2001. - No. 2. - P. 48.

[10] Dubinin V.F. Universal loaders [Text] / V.F. Dubinin, P.I. Pavlov, N.V. Khitrova // Rural mechanic. - 2002. - No. 2. - P. 27-28.

[11] RF patent No. 2083463, MKI B 65 G 67/24 // (B 65 G 65/22) Screw-milling feeder / P.I. Pavlov, N.V. Khitrova. - Publ. 10.07.97. Bul. No. 19.

[12] RF patent No. 2097481, MKI E 01 N 5/09 Auger milling feeder / P.I. Pavlov Publ. 01/30/96. Bul. No. 33. 